\title{
Kinetically Controlled Fischer Glycosidation under Flow Conditions: A New Method for Preparing Furanosides
}

\author{
Seiji Masuia \\ Yoshiyuki Manabea,b \\ Kohtaro Hirao \\ Atsushi Shimoyamaa,b \\ Takahide Fukuyamac \\ Ilhyong Ryu ${ }^{c}$ \\ Koichi Fukase *a,b (ID \\ a Department of Chemistry, Graduate School of Science, Osaka \\ University, 1-1 Machikaneyama-cho, Toyonaka, Osaka 560-0043, \\ Japan \\ koichi@chem.sci.osaka-u.ac.jp \\ ${ }^{\mathrm{b}}$ Core for Medicine and Science Collaborative Research and Educa- \\ tion, Project Research Center for Fundamental Sciences, Osaka \\ University, 1-1 Machikaneyama-cho, Toyonaka, Osaka 560-0043, \\ Japan \\ ' Department of Chemistry, Graduate School of Science, Osaka \\ Prefecture University, Sakai, Osaka 599-8531, Japan
}

Published as part of the 30 Years SYNLETT - Pearl Anniversary Issue
Received: 28.09.2018

Accepted after revision: 03.12.2018

Published online: 07.01.2019

DOI: 10.1055/s-0037-1611643; Art ID: st-2018-b0619-I

License terms: CCO

Abstract Kinetically controlled Fischer glycosidation was achieved under flow conditions. $\beta$-Hydroxy-substituted sulfonic acid functionalized silica (HO-SAS) was used as an acid catalyst. This reaction directly converted aldohexoses into kinetically favored furanosides to enable the practical synthesis of furanosides. After optimization of the reaction temperature and residence time, glucofuranosides, galactofuranosides, and mannofuranosides were synthesized in good yields.

Key words Fischer glycosidation, flow chemistry, furanosides, supported catalysis, carbohydrate, kinetically controlled reaction

Various furanosides occur naturally, such as those in plants, bacteria, protozoa, archaebacteria, and fungi, although furanosides only occur as nucleic acids in mammals. ${ }^{1}$ The most common furanoside is sucrose, which consists of glucopyranose and fructofuranose. L-Arabinofuranose and D-fructofuranose are main components of plant cell walls. Because galactofuranosides are essential for the growth of many pathogens, including Mycobacterium tuberculosis, Trypansoma cruzi, and Aspergillus fumigates, furanoside derivatives, which can inhibit the biosynthesis of furanose glycans, are expected to be drug candidates. ${ }^{1,2}$ In particular, inhibitors of uridine diphosphate (UDP)- $\alpha-D-$ pyranose mutase, which catalyzes the isomerization of UDP- $\alpha$-D-pyranose to UDP- $\alpha$-D-furanose, are being enthusiastically developed.

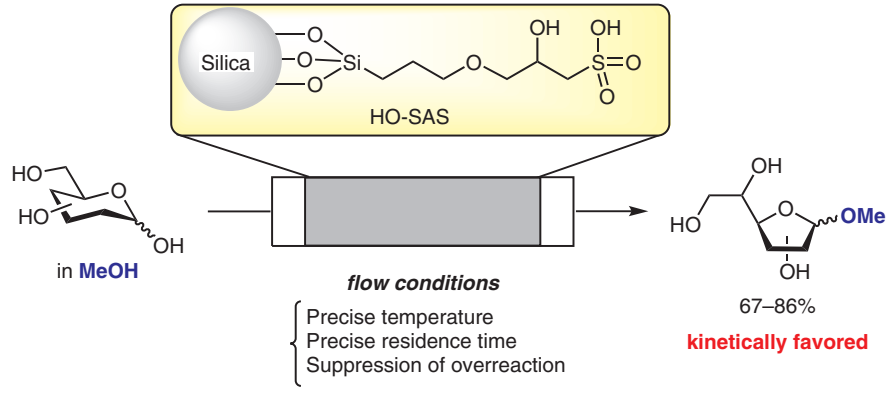

The simple and efficient syntheses of furanosides remain an important issue ${ }^{3}$ even though various synthetic methods have been reported, including the kinetically controlled cyclization of dithioacetals in alcohol, ${ }^{4}$ perbenzoylation of arabinose and galactose at high temperatures, ${ }^{5}$ reduction of D-galactono-1,4-lactone with disiamylborane, ${ }^{6}$ acetylation of hexoses and pentoses in the presence of boric acid, ${ }^{7}$ and the selective activation of the anomeric position using 2,4,6-trichloro-1,3,5-triazine-activated DMSO. ${ }^{8}$

Here, we achieved a concise synthesis of furanosides via kinetically controlled Fischer glycosidation. Fischer glycosidation ${ }^{9}$ of aldoses or ketoses is generally carried out in alcohols using acid catalysts. In this reaction, thermodynamically favored $\alpha$-pyranosides are preferentially obtained (Scheme 1), whereas Fisher glycosidation can provide furanosides under kinetically controlled conditions. ${ }^{10}$ Chelation by a specific metal can control which isomer is favored. Furanosides can be obtained as major products when $\mathrm{FeCl}_{3}$ is used as a Lewis acid. ${ }^{11}$ Microwave irradiation conditions were applied to this reaction, and the pyranosides/furano-

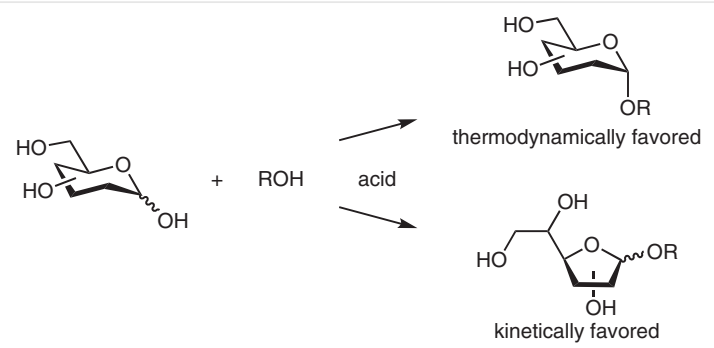

Scheme 1 Fischer glycosidation. Pyranosides are thermodynamically favored, whereas furanosides are kinetically favored. 
sides ratio and their $\alpha / \beta$ isomerization changed depending on the Lewis acid used. ${ }^{12}$ The addition of $\mathrm{CaCl}_{2}$ also improved the selectivity toward $\beta$-furanosides. ${ }^{13}$ However, the generation of a certain amount of pyranosides is inevitable. Because the stability of the furanoside chelates formed by various metals depends on their structure, challenges remain with respect to versatility in the preparation of various furanosides. In the present work, to overcome this drawback, we used a continuous flow system.

Continuous flow synthesis provides an innovative reaction control system that enables fast and efficient mixing, rapid heating and cooling, strict temperature control, and precise residence time control. ${ }^{14}$ Scalability is also an important advantage of flow reactions: scaled-up syntheses can be achieved with a flow system under the same conditions to realize the practical supply of target compounds. These excellent features have been applied to glycosylation reactions. Seeberger et al. first reported microflow glycosylation. ${ }^{15}$ We previously achieved stereoselective and efficient $\alpha$-sialylation, ${ }^{16} \beta$-mannosylation, ${ }^{17}$ and $N$-glycosylation $^{18}$ using efficient mixing and precise reaction temperature control under microflow conditions.

In this study, continuous flow synthesis was applied to Fisher glycosidation to obtain kinetically favored furanosides. Overreaction, i.e., conversion of furanosides to pyranosides, was suppressed through transfer of the products from the reaction system immediately after completion of the reaction.

We previously reported the acid-catalyzed dehydration reaction of alcohols under continuous flow conditions and the application of this reaction to the commercial production of pristane. ${ }^{19}$ Quantitative dehydration was achieved using one equivalent of strong acid under flash heating conditions. Immediate quenching completely suppressed the decomposition of alkenes, e.g., cationic isomerization and polymerization. In an acid-catalyzed dehydration reaction, generated water deactivates the acid catalyst, and the used acid must be neutralized during the workup. However, flow dehydration using a supported acid catalyst can overcome these issues. Generated water is washed out, and the acid catalyst can be kept active. Neutralization is not necessary. Sulfonic acid functionalized silica gel (SAS), which exhibits strongly acidity, a large surface area, and high thermal stability, ${ }^{20}$ has been widely used for the dehydration of sugars, ${ }^{21}$ glycerol, ${ }^{22}$ nitro alcohols, ${ }^{23}$ and chromanols. ${ }^{24}$ Dumesic et al. applied a flow dehydration process using SAS to the production of 5-hydroxymethylfurfural from fructose. ${ }^{21 \mathrm{~h}}$ We also achieved the dehydration of alcohols under flow conditions using $\beta$-hydroxy-substituted sulfonic acid functionalized silica (HO-SAS) ${ }^{25}$ with strong acidity and good stability and applied this process to the waste-free synthesis of pristane. ${ }^{19 b}$

In the present study, we achieved kinetically controlled Fischer glycosidations under flow conditions using HO-SAS to obtain furanosides (Scheme 1). The flow system used here is shown in Figure 1. A solution of sugar in alcohol was introduced into the column ( $\varphi 4.0 \mathrm{~mm} \times 50 \mathrm{~mm}$ ) packed with HO-SAS (350 mg, 0.9-1.0 mmol/g loading of $\mathrm{SO}_{3} \mathrm{H}$ ). The outlet of the flow system was connected to a back-pressure regulator (75 psi) to elevate the reaction temperature above the boiling point of the solvent. In this system, because the products can be removed from the reaction system, isomerization of furanosides to pyranosides can be suppressed. The narrow channel reduces the diffusion of the reaction mixture and enables flash heating, enabling precise control of the reaction time and the temperature. Therefore, this system is ideal for kinetic-controlled Fisher glycosidations.

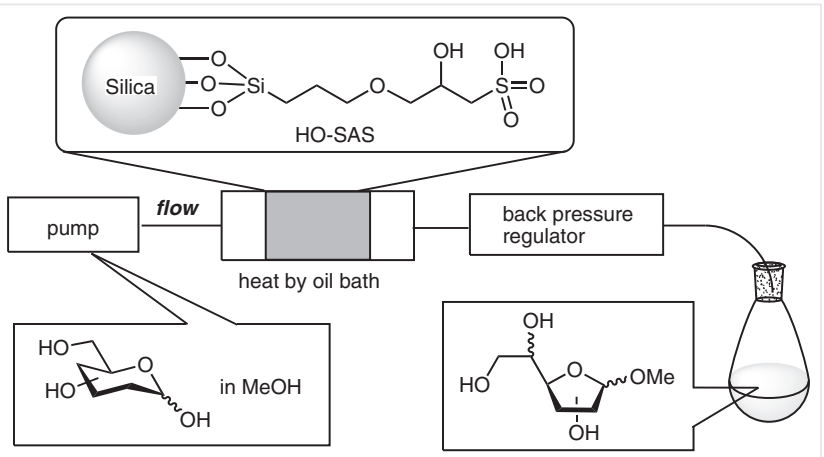

Figure 1 Flow setup for Fischer glycosidation under flow conditions using HO-SAS

Fischer glycosidation of glucose with methanol under flow conditions was first investigated (Table 1$).{ }^{26}$ A $0.1 \mathrm{M}$ glucose solution in methanol was introduced at a flow rate of $0.1 \mathrm{~mL} / \mathrm{min}$ into the column packed with HO-SAS (residence time: $5 \mathrm{~min}$ ). At room temperature, the reaction hardly proceeded; only a trace amount of furanosides $\mathbf{2}$ was observed (Table 1, entry 1 ). Elevating the reaction temperature increased the yield of $\mathbf{2}\left(28 \%\right.$ yield at $60{ }^{\circ} \mathrm{C}$ and $71 \%$ yield at $80^{\circ} \mathrm{C}$, respectively, Table 1, entries 2 and 3). By contrast, major products were changed to pyranosides 3 at 100 ${ }^{\circ} \mathrm{C}$ (Table 1 , entry 4 ). At $140{ }^{\circ} \mathrm{C}$, the products were decomposed and neither $\mathbf{2}$ nor $\mathbf{3}$ were recovered (Table 1, entry 5). When the residence time was shortened to $1 \mathrm{~min}$, furanosides 2 were obtained as the main products even at $100{ }^{\circ} \mathrm{C}$ (Table 1, entry 6). In entries 7 and $8, \mathrm{HCl}$ and $\mathrm{TsOH}$ were used as the acid catalyst instead of HO-SAS under flow conditions. $\mathrm{HCl}$ gave furanosides 2 with high selectivity but with low conversion (Table 1, entry 7), whereas TsOH resulted in higher conversion and lower selectivity (Table 1 , entry 8). These results indicate that the reactivity of HOSAS was higher than that of $\mathrm{HCl}$ and slightly lower than that of $\mathrm{TsOH}$.

The supported acid catalyst has several advantages over liquid catalysts, such as easy separation, simple workup, and reusability. The reaction using HO-SAS under batch 
Table 1 Fischer Glycosidation of Glucose (1) with Methanol under Flow Conditions

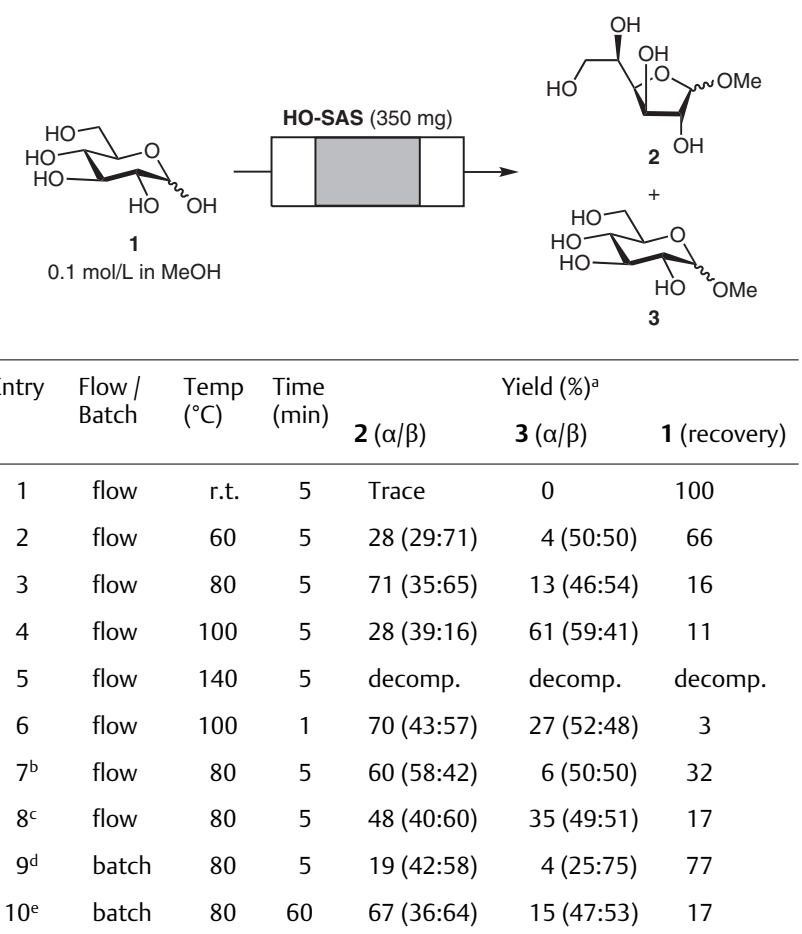

a Estimated by ${ }^{1} \mathrm{H}$ NMR using benzene as an internal standard.

${ }^{b} \mathrm{HCl}(1$ equiv., $0.1 \mathrm{M}$ ) is used instead of HO-SAS.

' $\mathrm{TsOH}$ ( 1 equiv., $0.1 \mathrm{M}$ ) is used instead of HO-SAS.

d HO-SAS ( $350 \mathrm{mg}$ ), sealed tube.

e HO-SAS $(350 \mathrm{mg})$, sealed tube.

conditions proceeded much slowly to give $\mathbf{2}$ in $19 \%$ yield after $5 \mathrm{~min}$ and in $67 \%$ after 60 min (Table 1, entries 9 and 10 ). The selectivity of $\mathbf{2}$ to $\mathbf{3}$ in the latter was slightly decreased compared to flow conditions (Table 1, entry 10). These results indicate that flash heating and efficient contact to HOSAS surface under flow conditions increase the reaction rate and furanosides selectivity.

To confirm the reusability of HO-SAS, the reaction was repeated six times without changing the HO-SAS (Scheme 2 ). The yields of glucofuranosides 2 were between $71 \%$ and $75 \%$ in all of the trials, and the average yield was $73 \%$. To demonstrate the scalability, the reaction was carried out using $1.73 \mathrm{~g}$ ( $9.61 \mathrm{mmol})$ of glucose (1) to give furanosides $2(1.33 \mathrm{~g})$ in $71 \%$ yield. Considering $350 \mathrm{mg}$ of HO-SAS (0.9$1.0 \mathrm{mmol} / \mathrm{g}$ loading of $\mathrm{SO}_{3} \mathrm{H}$ ) was packed in the column, the acidity was not reduced after 25 catalytic cycles.

The kinetically controlled flow Fischer glycosidations under flow conditions were then applied to other sugars (Scheme 3). To maximize the yields of furanosides, the reaction temperature and residence time were optimized. Although isomerization of mannofuranosides $\mathbf{5}$ to mannopyranosides was faster than the isomerization of glucose, a high temperature $\left(100{ }^{\circ} \mathrm{C}\right)$ and short residence time $(0.5$ $\mathrm{min}$ ) gave a moderate yield of $\mathbf{5}$ (67\%). In this case, lower
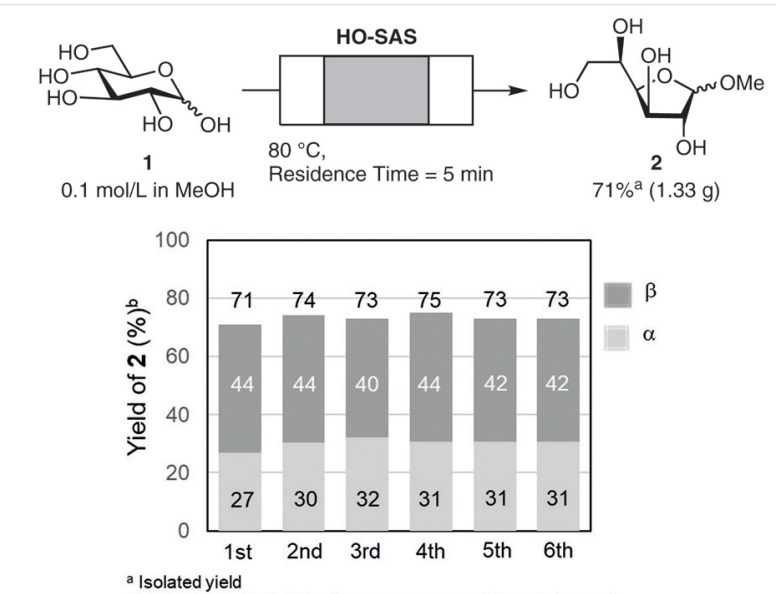

b Estimated by ${ }^{1} \mathrm{H}$ NMR using benzene as an internal standard

Scheme 2 Investigation of reusability of HO-SAS
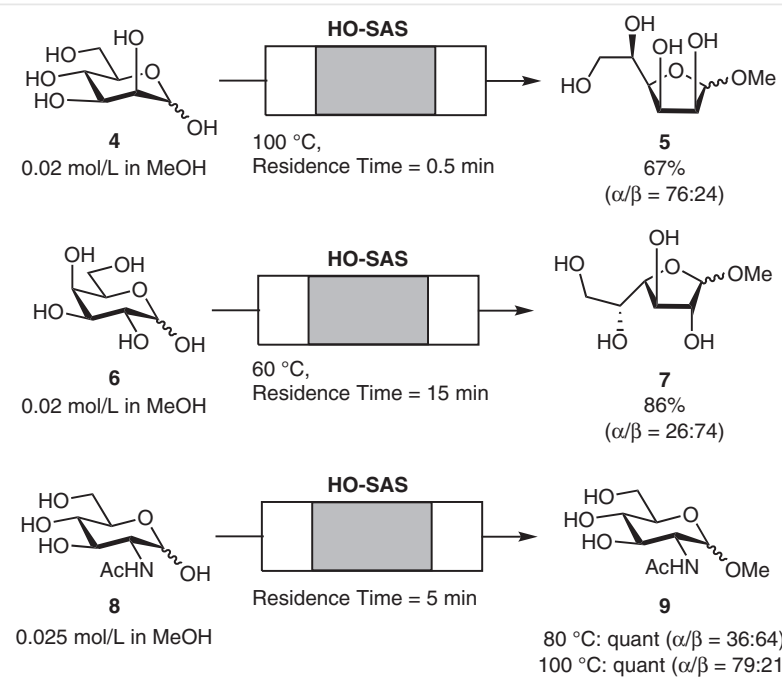

Scheme 3 Kinetically controlled Fischer glycosidation of mannose (4), galactose (6), and $N$-acetylglucosamine (8). The yields and the $\alpha / \beta$ ratio were estimated by NMR spectroscopy.

concentration gave better results $(0.02 \mathrm{~mol} / \mathrm{L}: 67 \%, 0.1$ $\mathrm{mol} / \mathrm{L}: 59 \%)$. On the other hand, galactofuranosides 7 were readily produced: the reaction at $60{ }^{\circ} \mathrm{C}$ for $15 \mathrm{~min}$ gave 7 in $86 \%$ yield. In this reaction, low concentration $(0.02 \mathrm{~mol} / \mathrm{L})$ was required because of the low solubility of galactose $(\mathbf{6})$ in methanol.

In the case of $\mathrm{N}$-acetyl-glucosamine, only pyranosides $\mathbf{9}$ were obtained, without the formation of furanosides. Interestingly, elevating the reaction temperature from $80{ }^{\circ} \mathrm{C}$ to $100{ }^{\circ} \mathrm{C}$ changed the $\alpha / \beta$ ratio of 9 from 36:64 to 79:21. These results suggest that the Fisher glycosidation of $\mathrm{N}$-acetyl-glucosamine $(\mathbf{8})$ predominantly proceeded without a ring-opening process because of the rapid dehydration assisted by the acetamide group. The reaction-temperature dependence of the $\alpha / \beta$ ratio can be explained by the fact 
that the $\beta$-isomer is kinetically favored because of neighboring participation, whereas the $\alpha$-isomer is thermodynamically favored because of the anomeric effect.

In summary, we achieved Fisher glycosidation under flow conditions using HO-SAS as a solid acid catalyst. In this system, both kinetically favored furanosides and thermodynamically favored pyranosides were obtained through control of the reaction temperature and the residence time. We successfully demonstrated that flow Fischer glycosidation can be a powerful and practical method to prepare furanosides.

\section{Funding Information}

This work was financially supported in part by JSPS KAKENHI Grant Number $15 \mathrm{H} 05836$ in Middle Molecular Strategy, JSPS KAKENHI Grant Number 16H01885, JSPS KAKENHI Grant Number 16H05924, and JSPS KAKENHI Grant Number 18H04620.

\section{Supporting Information}

Supporting information for this article is available online at https://doi.org/10.1055/s-0037-1611643.

\section{References and Notes}

(1) Peltier, P.; Euzen, R.; Daniellou, R.; Nugier-Chauvin, C.; Ferrières, V. Carbohydr. Res. 2008, 343, 1897.

(2) (a) de Lederkremer, R. M.; Colli, W. Glycobiology 1995, 5, 547. (b) Pedersen, L. L.; Turco, S. J. Cell. Mol. Life Sci. 2003, 60, 259. (c) Lucia, M.-P.; Adriane, R. T.; Norton, H.; Orlando, A. A.; Wagner, B. D.; Jose, O. P. Curr. Org. Chem. 2008, 12, 926. (d) Richards, M. R.; Lowary, T. L. ChemBioChem 2009, 10, 1920. (e) Umesiri, F. E.; Sanki, A. K.; Boucau, J.; Ronning, D. R.; Sucheck, S. J. Med. Res. Rev. 2010, 30, 290.

(3) Imamura, A.; Lowary, T. Trends Glycosci. Glycotechnol. 2011, 23, 134.

(4) (a) Completo, G. C.; Lowary, T. L. J. Org. Chem. 2008, 73, 4513. (b) Green, J. W.; Pacsu, E. J. Am. Chem. Soc. 1937, 59, 1205. (c) McAuliffe, J. C.; Hindsgaul, O. J. Org. Chem. 1997, 62, 1234. (d) Timmer, M. S. M.; Stocker, B. L.; Seeberger, P. H. J. Org. Chem. 2006, 71, 8294 .

(5) (a) D'Accorso, N. B.; Thiel, I. M. E.; Schüller, M. Carbohydr. Res. 1983, 124, 177. (b) Gallo-Rodriguez, C.; Varela, O.; de Lederkremer, R. M. Carbohydr. Res. 1997, 305, 163. (c) Lee, R. E.; Mikusova, K.; Brennan, P. J.; Besra, G. S. J. Am. Chem. Soc. 1995, $117,11829$.

(6) Varela, O.; Marino, C.; de Lederkremer, R. M. Carbohydr. Res. 1986, 155, 247.

(7) Furneaux, R. H.; Rendle, P. M.; Sims, I. M. J. Chem. Soc., Perkin Trans. 1 2000, 2011.

(8) Shi, Z.; Sun, L.; Li, C. J. Agric. Food. Chem. 2014, 62, 3287.

(9) (a) Fischer, E. Ber. Dtsch. Chem. Ges. 1893, 26, 2400. (b) Fischer, E. Ber. Dtsch. Chem. Ges. 1895, 28, 1145. (c) Fischer, E.; Beensch, L. Ber. Dtsch. Chem. Ges. 1894, 27, 2478.

(10) (a) Arasappan, A.; Fraser-Reid, B. Tetrahedron Lett. 1995, 36, 7967. (b) Ferrières, V.; Bertho, J.-N.; Plusquellec, D. Carbohydr. Res. 1998, 311, 25. (c) Haworth, W. N.; Porter, C. R. J. Chem. Soc. (Res.) 1929, 2796. (d) Velty, R.; Benvegnu, T.; Gelin, M.; Privat, E.; Plusquellec, D. Carbohydr. Res. 1997, $299,7$.
(11) Lubineau, A.; Fischer, J.-C. Synth. Commun. 1991, 21, 815.

(12) Santra, S.; Jonas, E.; Bourgault, J.-P.; El-Baba, T.; Andreana, P. R. J. Carbohydr. Chem. 2011, 30, 27.

(13) Ferrières, V.; Bertho, J.-N.; Plusquellec, D. Tetrahedron Lett. 1995, 36, 2749 .

(14) (a) Newman, S. G.; Jensen, K. F. Green Chem. 2013, 15, 1456. (b) Gutmann, B.; Cantillo, D.; Kappe, C. O. Angew. Chem. Int. Ed. 2015, 54, 6688.

(15) Ratner, D. M.; Murphy, E. R.; Jhunjhunwala, M.; Snyder, D. A.; Jensen, K. F.; Seeberger, P. H. Chem. Commun. 2005, 578.

(16) (a) Tanaka, S.-I.; Goi, T.; Tanaka, K.; Fukase, K. J. Carbohydr. Chem. 2007, 26, 369. (b) Tanaka, K.; Fujii, Y.; Tokimoto, H.; Mori, Y.; Tanaka, S.-I.; Bao, G.-M.; Siwu, E. R. O.; Nakayabu, A.; Fukase, K. Chem. Asian J. 2009, 4, 574. (c) Uchinashi, Y.; Nagasaki, M.; Zhou, J.; Tanaka, K.; Fukase, K. Org. Biomol. Chem. 2011, 9, 7243. (d) Uchinashi, Y.; Tanaka, K.; Manabe, Y.; Fujimoto, Y.; Fukase, K. J. Carbohydr. Chem. 2014, 33, 55.

(17) Tanaka, K.; Mori, Y.; Fukase, K. J. Carbohydr. Chem. 2009, $28,1$.

(18) Tanaka, K.; Miyagawa, T.; Fukase, K. Synlett 2009, 1571.

(19) (a) Tanaka, K.; Motomatsu, S.; Koyama, K.; Tanaka, S.-I.; Fukase, K. Org. Lett. 2007, 9, 299. (b) Furuta, A.; Hirobe, Y.; Fukuyama, T.; Ryu, I.; Manabe, Y.; Fukase, K. Eur. J. Org. Chem. 2017, 1365.

(20) (a) Gholamzadeh, P.; Mohammadi Ziarani, G.; Lashgari, N.; Badiei, A.; Asadiatouei, P. J. Mol. Catal. A: Chem. 2014, 391, 208. (b) Mohammadi Ziarani, G.; Lashgari, N.; Badiei, A. J. Mol. Catal. A: Chem. 2015, 397, 166.

(21) (a) Agirrezabal-Telleria, I.; Requies, J.; Güemez, M. B.; Arias, P. L. Appl. Catal., B 2012, 115, 169. (b) Crisci, A. J.; Tucker, M. H.; Dumesic, J. A.; Scott, S. L. Top. Catal. 2010, 53, 1185. (c) Crisci, A. J.; Tucker, M. H.; Lee, M.-Y.; Jang, S. G.; Dumesic, J. A.; Scott, S. L. ACS Catal. 2011, 1, 719. (d) Jeong, G. H.; Kim, E. G.; Kim, S. B.; Park, E. D.; Kim, S. W. Microporous Mesoporous Mater. 2011, 144, 134. (e) Liu, B.; Zhang, Z. RSC Adv. 2013, 3, 12313. (f) Saravanamurugan, S.; Riisager, A. Catal. Commun. 2012, 17, 71. (g) Shi, X.; Wu, Y.; Yi, H.; Rui, G.; Li, P.; Yang, M.; Wang, G. Energies 2011, 4, 669. (h) Tucker, M. H.; Crisci, A. J.; Wigington, B. N.; Phadke, N.; Alamillo, R.; Zhang, J.; Scott, S. L.; Dumesic, J. A. ACS Catal. 2012, 2, 1865. (i) van der Graaff, W. N. P.; Olvera, K. G.; Pidko, E. A.; Hensen, E. J. M. J. Mol. Catal. A: Chem. 2014, 388, 81.

(22) Lourenço, J. P.; Macedo, M. I.; Fernandes, A. Catal. Commun. 2012, 19, 105.

(23) Sasidharan, M.; Bhaumik, A. J. Mol. Catal. A: Chem. 2013, 367, 1.

(24) Kureshy, R. I.; Ahmad, I.; Pathak, K.; Khan, N. H.; Abdi, S. H. R.; Jasra, R. V. Catal. Commun. 2009, 10, 572.

(25) Available from MiChS Co. Ltd: http://www.michs.jp; for applications of HO-SAS for flow esterification, see: Furuta, A.; Fukuyama, T.; Ryu, I. Bull. Chem. Soc. Jpn. 2017, 90, 607.

(26) General Procedure

A flow reactor system consisting of syringe pump, column $(\varphi$ $4.0 \mathrm{~mm} \times 50 \mathrm{~mm}$, filled with HO-SAS $(350 \mathrm{mg}, 0.9-1.0 \mathrm{mmol} / \mathrm{g}$ loading of $\mathrm{SO}_{3} \mathrm{H}$ ), backpressure regulator and tubes (inner diameter $\varphi=50 \mu \mathrm{m}$, length $\mathrm{L} 1=40 \mathrm{~cm}, \mathrm{~L} 2=10 \mathrm{~cm}, \mathrm{~L} 3=20 \mathrm{~cm}$ ) was used. A solution of glucose $(\mathbf{1}, 90 \mathrm{mg}, 0.5 \mathrm{mmol})$ in methanol (5 $\mathrm{mL}, 0.10 \mathrm{M}$ glucose solution) was filled in the syringe. The syringe was pumped using the syringe pump at flow rates of 0.1 $\mathrm{mL} / \mathrm{min}$ (residence time $=5 \mathrm{~min}$ ), and the reaction solution was passed through the column filled with HO-SAS. After the reaction solution came out, the solution was send to the waste for 3 min (priming time $=3 \mathrm{~min}$ ). Then, the solution was collected for $10 \mathrm{~min}$. After concentration in vacuo, the crude mixture was analyzed by NMR spectroscopy. New HO-SAS was packed each experiments except for the experiments in Scheme 2. 